\title{
Whey Protein Isolate
}

National Cancer Institute

\section{Source}

National Cancer Institute. Whey Protein Isolate. NCI Thesaurus. Code C67285.

A biologically active, cystine-rich, whey-based protein isolate. Whey protein isolate is broken down in the body into cystine and glutamylcystine, which travel safely in the blood stream, upon cell entry, deliver a sustained amount of free cysteine to the cells. The available cysteine allows cells to synthesize glutathione (GSH), a tripeptide containing amino acids glycine, glutamate and cysteine, thereby maintaining and increasing intracellular GSH concentrations. GSH plays a major role as an antioxidant, thereby protecting cells from oxidative damage due to harmful substances such as free radicals and reactive oxygen compounds. 